\title{
FAKTOR-FAKTOR YANG MEMENGARUHI KEPATUHAN DIET PASIEN GAGAL GINJAL KRONIK YANG MENDAPAT TERAPI HEMODIALISA DI RUANG HEMODIALISA RSUD Dr. PIRNGADI KOTA MEDAN TAHUN 2015
}

\author{
Amira Permata Sari Tarigan, Endang Susilawati, Chandra F. Zendrato \\ Jurusan Keperawatan Poltekkes Kemenkes Medan
}

\begin{abstract}
Chronic kidney failure patients treated by hemodialysis therapy should be consistent in participating in dieting program in order to forestall the incidence of nutrition deficiency, liquid and electrolyte imbalance, and the incidence of the excessive accumulation of metabolism residual. Compliance in dieting program is one of the factors which contribute to the success or failure in hemodialysis therapy. The objective of the research was to find out some factors which influenced compliance in dieting of chronic kidney failure patients who got hemodialysis therapy in Hemodialysis Room of RSUD dr. Pirngadi, Medan. The research used descriptive method with cross sectional design. The samples were 35 respondents, taken by using purposive sampling technique. The instruments of the research were questionnaires and food recall. The result of the research showed that 19 respondents (54.3\%) did not quite understand the instruction, 26 respondents $(74.3 \%)$ had good interaction, 21 respondents (60\%) lack of support, 31 respondents $(88.6 \%)$ did not comply with dieting program, and 4 respondents (11.4\%) complied with dieting program. The factor which influenced the compliance of the majority of patients was interaction quality. Patients had good understanding in instruction, good interaction quality, and family support. Only a small number of patients complied with dieting. Patients' awareness of diet is very important. The majority of patients did not comply with dieting program.
\end{abstract}

Keywords : Compliance, Chronic Kidney Failure, Hemodialysis

\section{PENDAHULUAN}

Gagal Ginjal kronis atau penyakit renal tahap akhir/ESDR (end-stage renal disease) merupakan gangguan fungsi renal yang progresif dan irreversibel dimana kemampuan tubuh gagal untuk mempertahankan metabolisme dan keseimbangan cairan dan elektrolit, menyebabkan uremia (retensi urea dan sampah nitrogen lain dalam darah). Ini dapat disebabkan oleh penyakit sistemik seperti diabetes melitus (DM), glomerulonefritis kronis, pielonefritis, hipertensi yang tidak dapat di kontrol, obstruksi traktus urinarius, lesi herideter, infeksi, medikasi atau agen toksik (Bruner \& Suddarth, 2002).

Pada peyakit ginjal tahap akhir renal replacement therapy diperlukan untuk memperpanjang hidup (Barnet et all, 2007). Terapi penggantian ginjal dapat berupa hemodialisis, peritoneal dialysis dan transplantasi ginjal. Terapi penggantian ginjal tidak hanya untuk memperpanjang hidup akan tetapi juga mengembalikan kualitas hidup dengan meningkatkan kemandirian pasien. Bagi penderita gagal ginjal kronis, hemodialisis akan mencegah kematian. Namun demikian hemodialisis tidak menyembuhkan atau memulihkan penyakit ginjal. Pasien akan tetap mengalami sejumlah permasaahan dan komplikasi serta adanya berbagai perubahan pada bentuk dan fungsi sistem dalam tubuh (Smeltzer \& Bare, 2008)
Data WHO menunjukkan, penyakit gagal ginjal dan saluran kemih telah menyumbang 850.000 kematian setiap tahunnya. Hal ini membuktikan bahwa penyakit gagal ginjal kronik menduduki peringkat ke-12 tertinggi angka kematian atau angka ke-17 angka kecacatan, hingga tahun 2015 WHO memperkirakan sebanyak 36 juta orang di dunia meninggal akibat gagal ginjal kronik (Ali, 2014).

Penderita gagal ginjal kronik (GGK) semakin meningkat jumlahnya pada tahun 2011, di indonesia terdapat 15.535 pasien yang baru menjalani hemodialisa dan pada tahun 2012 terjadi peningkatan pasien yang menjalani hemodialisa sebanyak 4.086 orang sehingga secara keseluruhan terdapat 19.621 pasien yang baru menjalani hemodilisa. Sampai akhir tahun 2012 terdapat 244 unit hemodialisis di indonesia. Di sumatera utara jumlah diagnosa penyakit utama pasien hemodialisa sebanyak 503 pasien (Indonesian Renal Registry, 2012)

Penurunan fungsi ginjal mengharuskan pasien menjalani terapi hemodialisa sepanjang hidupnya. Biasanya pasien melakukan 2-3 kali seminggu selama 3-4 jam per sekali hemodialisa (Bruner \& Suddarth, 2002). Terapi pengganti ginjal ini menjadi salah satu pilihan bagi pasien penyakit gagal ginjal tahap akhir untuk mempertahankan fungsi tubuh (Lemone \& Burke, 2008)

Penyebab tingginya angka kasus gagal ginjal yang menjalankan terapi hemodialisa di pengaruhi banyak faktor 
yaitu perubahan gaya hidup, pola makan tinggi lemak dan karbohidrat, juga penyebab lainnya seperti penyakit genetic yaitu kelainan kekebalan dan cacat lahir (Syamsyir \& Iwan, 2008).

Hemodialisa adalah salah satu tindakan yang dilakukan pada kasus gagal ginjal. Ketika ginjal tidak dapat bekerja dengan baik, sampah sisa metabolisme dari apa yang dimakan dan diminum akan menumpuk di dalam tubuh karena tidak dapat dikeluarkan ginjal, hal inilah mengapa gagal ginjal terminal yang menjalani hemodialisa banyak hal yang harus diperhatikan diantaranya adalah program diet (Noviyanti, 2013).

Tujuan terapi diet dan intervensi nutrisi pada pasien yang dilakukan hemodialisa adalah untuk mencapai dan menjaga status nutrisi yang baik, mencegah atau menghambat penyakit, mencegah atau memperlambat penyakit kardiovaskular, cerebrovaskular dan penyakit vaskular perifer, untuk mencegah atau menangani hiperpartiroidisme dan bentuk-bentuk lain dari osteodystrophy ginjal dan untuk mencegah atau memperbaiki keracunan uremik dan gangguan metabolic lain yang dipengaruhi nutrisi, yang terjadi pada gagal ginjal dan tidak dapat teratasi secara adekuat dengan hemodialisis (Cahyaningsih, 2011).

Diet cukup sulit dan diet sukar diikuti oleh pasien karena sering timbul perasaan bosan jika hanya mengkonsumsi makanan yang disarakan oleh rumah sakit. Nafsu makan pasien dalam batas diet yang sudah ditetapkan. Perencanaan pengaturan diet cukup sulit oleh pasien akan tetapi bila itu tidak dipatuhi akan memberikan konsekuensi yang merugikan dan akan memercepat dari jadwal terapi yang akan ditentukan dan akan memperberat biaya terapi (Almatsier, 2008).

Seseorang yang telah menjalani terapi hemodialisa kemudian tidak menjalankan program diet dengan baik maka akan terjadi defisiensi gizi, keseimbangan cairan dan elektrolit akan terganggu dan akan terjadi akumulasi produk sisa metabolisme (uremia) yang berlebihan sehingga akan mempercepat dari jadwal terapi yang akan ditentukan dan akan memperberat biaya dari terapi (Almatsier, 2008).

Berdasarkan penelitian Kamaludin \& Rahayu (2009) dari 51 responden peneliti mendapatkan 67,3\% penderita yang patuh dan $32,7 \%$ yang tidak patuh dalam mengurangi asupan cairan pada RSUD Prof Dr. Margono Soekarjo Puwerkerto, angka ini lebih rendah dari penelitiannya Siwi Ikaristi yang mengatakan 64,29\% penderita gagal ginjal kronik tidak patuh dalam mengurangi asupan cairan pada rumah sakit Panti Rapih Yogyakarta.

Berdasarkan hasil penelitian Desitasari, Utami, \& Misrawati (2014) pada RSUD Arifin Achmad Pekanbaru tentang hubungan pengetahuan, sikap dan dukungan keluarga dengan kepatuhan diet pasien gagal ginjal kronik yang menjalani hemodialisa dapat disimpulkan bahwa gambaran data demografi karakteristik didapatkan mayoritas responden berjenis kelamin laki-laki $(61,1 \%)$, usia 40-60 tahun $(69,4 \%)$, pendidikan terakhir SMA $(33,3 \%)$, tidak bekerja $(52,8 \%)$, patuh terhadap diet
$(72,2 \%)$, lamanya menjalani hemodialisa selama $>6$ tahun $(47,2 \%)$.

Berdasarkan penelitian Bame, Petersen \& Wray (1993) pada pusat dialisis Los Angeles, Amerika Serikat didapatkan hasil ketidakpatuhan pasien dialisis secara umum meliputi 4 (empat) aspek yaitu ketidakpatuhan mengikuti program hemodialisis (0 \% - 32,3 \%), ketidakpatuhan dalam program pengobatan $(1,2 \%-81 \%)$, ketidakpatuhan terhadap restriksi cairan $(3,4 \%-74 \%)$ dan ketidakpatuhan mengikuti program diet $(1,2-82,4 \%)$. Kepatuhan pasien gagal ginjal kronik yang mendapat terapi hemodialisa, terdapat pasien yang tidak patuh terhadap semua regimen hemodialisa sehingga dapat memengaruhi kualitas hidup, meningkatnya biaya perawatan kesehatan, meningkatnya morbiditas, dan mortilitas pasien (Kim et all, 2010).

Berdasarkan survei pendahuluan di RSUD Dr. Pirngadi Kota Medan didapat jumlah pasien penderita gagal ginjal kronik periode Januari sampai Desember tahun 2014 berjumlah 16.198 orang dan yang menjalani hemodialisa berjumlah 2.008 orang dan pada bulan Oktober-Desember berjumlah 524 dan rata-rata perbulan berjumlah 175 orang.

Mengingat begitu banyaknya kerugian apabila pasien yang mendapat terapi hemodialisa tidak patuh tehadap pola diet maka hendaknya setiap pasien harus patuh dan tidak boleh melanggar terhadap pola diet yang diberikan.

Untuk itu penulis tertarik untuk mengadakan penelitian tentang Faktor-Faktor Yang Memengaruhi Kepatuhan Diet Pasien Gagal Ginjal Kronik yang Mendapat Terapi Hemodialisa di Ruang Hemodialisa RSUD Dr. Pirngadi Kota Medan 2015.

\section{METODE PENELITIAN}

Jenis penelitian yang digunakan adalah penelitian deskriptif dan desain penelitian yang digunakan adalah cross sectional.

Populasi dalam penelitian ini adalah pasien yang menjalani terapi Hemodialisa di ruang Hemodialisa RSUD Dr. Pirngadi Medan. Sampel pada penelitian ini sebanyak 35 orang yang memenuhi kriteria inklusi dengan metode pengambilan sampel purposive sampling.

Pengumpulan data dalam penelitian ini adalah dilakukan dengan membagikan kuesioner yang berisi pertanyaan dan terlebih dahulu menjelaskan tujuan penelitian. Bila bersedia menjadi responden, dipersilahkan untuk menandatangani surat persetujuan dan selanjutnya diberikan penjelasan tentang pengisian kuesioner, pengumpulan data untuk kepatuhan dengan cara food recall yaitu peneliti menanyakan jumlah takaran makanan yang dikonsumsi dalam 3 hari terakhir.

Penelitian ini dilakukan analisa univariat bertujuan untuk menjelaskan atau mendeskripsikan karakteristik setiap variabel penelitian dan disajikan dalam bentuk tabel distribusi frekuensi. 


\section{HASIL PENELITIAN}

1. Pemahaman Tentang Instruksi

Tabel 4.1 Distribusi Frekuensi Responden Berdasarkan Pemahaman Tentang Instruksi Di Ruang Hemodialisa RSUD Dr. Pirngadi Kota Medan Tahun 2015

\begin{tabular}{cccc}
\hline No & $\begin{array}{c}\text { Pemahaman } \\
\text { Tentang } \\
\text { Instruksi }\end{array}$ & Frekuensi & \% \\
& Paham & 15 & 42,9 \\
\hline 1 & Kurang paham & 19 & 54,3 \\
2 & Tidak Paham & 1 & 2.9 \\
\hline 3 & Jumlah & 35 & 100 \\
\hline
\end{tabular}

Berdasarkan tabel diatas dapat dilihat bahwa mayoritas pemahaman tentang instruksi responden adalah kurang paham dibandingkan responden yang paham dan tidak paham.

2. Kualitas Interaksi

Tabel 4.2 Distribusi Frekuensi Responden Berdasarkan Kualitas Interaksi Di Ruang Hemodialisa RSUD Dr. Pirngadi Kota Medan Tahun 2015

\begin{tabular}{cccc}
\hline No & $\begin{array}{c}\text { Kualitas } \\
\text { Interaksi }\end{array}$ & Frekuensi & \% \\
\hline 1 & Baik & 26 & 74,3 \\
2 & Kurang baik & 9 & 25,7 \\
3 & Tidak baik & 0 & 0 \\
\hline & Jumlah & 35 & 100 \\
\hline
\end{tabular}

Berdasarkan tabel diatas dapat dilihat bahwa mayoritas kualitas interaksi responden adalah baik dibandingkan responden yang kurang baik dan tidak baik.

3. Dukungan Keluarga

Tabel 4.3 Distribusi Frekuensi Responden Berdasarkan Dukungan Keluarga Di Ruang Hemodialisa RSUD Dr. Pirngadi Kota Medan Tahun 2015

\begin{tabular}{cccc}
\hline No & $\begin{array}{c}\text { Dukungan } \\
\text { Keluarga }\end{array}$ & Frekuensi & \% \\
\hline 1 & Mendukung & 14 & 40 \\
2 & $\begin{array}{c}\text { Kurang } \\
\text { mendukung } \\
\text { Tidak } \\
\text { mendukung }\end{array}$ & 21 & 60 \\
3 & 0 & 0 \\
\hline & Jumlah & 35 & 100 \\
\hline
\end{tabular}

Berdasarkan tabel diatas dapat dilihat bahwa mayoritas dukungan keluarga responden adalah kurang mendukung dibandingkan responden yang mendukung dan tidak mendukung.
4. Kepatuhan

Tabel 4.4 Distribusi Frekuensi Responden Berdasarkan Kepatuhan Di Ruang Hemodialisa RSUD Dr. Pirngadi Kota Medan Tahun 2015

\begin{tabular}{cccc}
\hline No & Kepatuhan & Frekuensi & \% \\
\hline 1 & Patuh & 4 & 11,4 \\
2 & Tidak patuh & 31 & 88,6 \\
\hline & Jumlah & 35 & 100 \\
\hline
\end{tabular}

Berdasarkan tabel diatas dapat dilihat bahwa mayoritas responden adalah yang tidak patuh dibandingakan responden yang patuh.

Tabel 4.5 Distribusi Frekuensi Tingkat Kepatuhan Responden Berdasarkan Pemahaman Tentang Instruksi Di Ruang Hemodialisa RSUD Dr. Pirngadi Kota Medan Tahun 2015

\begin{tabular}{cccccccc}
\hline & Pemahaman & \multicolumn{4}{c}{ Tingkat Kepatuhan } & \multicolumn{2}{c}{ Total } \\
\cline { 3 - 8 } No & $\begin{array}{c}\text { Tentang } \\
\text { Instruksi }\end{array}$ & $\begin{array}{c}\text { Pat } \\
\text { uh }\end{array}$ & $\begin{array}{c}\text { \% } \\
\text { Tidak } \\
\text { Patuh }\end{array}$ & \% & Jlh & $\%$ \\
\hline 1 & Paham & 4 & 11,4 & 11 & 31,4 & 15 & 42,9 \\
2 & Kurang paham & 0 & 0 & 19 & 54,3 & 19 & 54,3 \\
3 & Tidak paham & 0 & 0 & 1 & 2,9 & 1 & 2,9 \\
\hline & Jumlah & $\mathbf{4}$ & $\mathbf{1 1 , 4}$ & $\mathbf{3 1}$ & $\mathbf{8 8 , 6}$ & $\mathbf{3 5}$ & $\mathbf{1 0 0}$ \\
\hline
\end{tabular}

Dari tabel diatas dapat dilihat bahwa jumlah reponden yang memiliki pemahaman instruksi yang kurang paham dan tidak patuh lebih banyak dibandingkan reponden yang paham dan patuh. Responden yang paham dan patuh jauh lebih baik dibandingkan responden yang kurang paham dan tidak paham tentang instruksi.

Tabel 4.6 Distribusi Frekuensi Tingkat Kepatuhan Responden Berdasarkan Kualitas Interaksi Di Ruang Hemodialisa RSUD Dr. Pirngadi Kota Medan Tahun 2015

\begin{tabular}{cccccccc}
\hline \multirow{2}{*}{ No } & \multirow{2}{*}{ Kualitas } & \multicolumn{3}{c}{ Tingkat Kepatuhan } & \multicolumn{2}{c}{ Total } \\
\cline { 3 - 8 } & Interaksi & Patuh & $\%$ & $\begin{array}{c}\text { Tidak } \\
\text { Patuh }\end{array}$ & \% & Jumla & \multirow{2}{*}{ h } \\
\hline 1 & Baik & 4 & 11,4 & 22 & 62,9 & 26 & 74,3 \\
2 & Kurang baik & 0 & 0 & 9 & 25,7 & 9 & 25,7 \\
3 & Tidak baik & 0 & 0 & 0 & 0 & 0 & 0 \\
\hline & Jumlah & $\mathbf{4}$ & $\mathbf{1 1 , 4}$ & $\mathbf{3 1}$ & $\mathbf{8 8 , 6}$ & $\mathbf{3 5}$ & $\mathbf{1 0 0}$ \\
\hline
\end{tabular}

Dari tabel diatas dapat dilihat bahwa jumlah reponden yang memiliki kualitas interaksi yang baik dan tidak patuh lebih banyak dibandingkan reponden yang memiliki kualitas interaksi yang baik dan patuh. Responden yang patuh dan memiliki kualitas interaksi yang baik, jauh lebih baik dibandingkan responden yang memiliki kualitas interaksi kurang baik.

Tabel 4.7 Distribusi Frekuensi Tingkat Kepatuhan Responden Berdasarkan Dukungan Keluarga Di Ruang Hemodialisa RSUD Dr. Pirngadi Kota Medan Tahun 2015

\begin{tabular}{ccccccccc}
\hline & \multirow{2}{*}{ No } & Dukungan & \multicolumn{4}{c}{ Tingkat Kepatuhan } & \multicolumn{2}{c}{ Total } \\
\cline { 3 - 8 } & Keluarga & $\begin{array}{c}\text { Patu } \\
\text { h }\end{array}$ & $\boldsymbol{\%}$ & $\begin{array}{c}\text { Tidak } \\
\text { Patuh }\end{array}$ & $\%$ & Jlh & \multirow{2}{*}{$\%$} \\
\hline 1 & Mendukung & 4 & 11,4 & 10 & 28,6 & 14 & 40 \\
2 & Kurang mendukung & 0 & 0 & 21 & 60 & 21 & 60 \\
3 & Tidak mendukung & 0 & 0 & 0 & 0 & 0 & 0 \\
\hline & Jumlah & $\mathbf{4}$ & $\mathbf{1 1 , 4}$ & $\mathbf{3 1}$ & $\mathbf{8 8 , 6}$ & $\mathbf{3 5}$ & $\mathbf{1 0 0}$ \\
\hline
\end{tabular}


Dari tabel diatas dapat dilihat bahwa jumlah reponden yang kurang mendapat dukungan dari keluarga dan tidak patuh lebih banyak dibandingkan reponden yang mendapat dukungan dari keluarga dan patuh. Responden mendapat dukungan dari keluarga dan patuh, jauh lebih baik dibandingkan responden kurang mendapat dukungan dari keluarga.

\section{PEMBAHASAN}

\section{Pemahaman Tentang Instruksi}

Hasil penelitian yang didapat oleh peneliti menunjukkan bahwa mayoritas pemahaman responden tentang instruksi yaitu kurang paham dan tidak patuh. Pemahaman responden tentang instruksi termasuk kategori kurang paham dan tidak patuh disebabkan karena instruksi yang diperoleh dari tenaga kesehatan sulit dipahami dan dimengerti oleh responden. Notoatmodjo (2007) menyatakan bahwa pemahaman sebagai bagian dari pengetahuan merupakan domain yang sangat penting untuk terbentuknya tindakan seseorang.

Ley dan Spelman tahun 1967 (dalam Niven, 2002) dalam penelitiannya menemukan bahwa lebih dari $60 \%$ yang diwawancarai setelah bertemu dengan dokter salah mengerti tentang instruksi yang diberikan kepada mereka. Kadang-kadang hal ini disebabkan oleh kegagalan profesional kesehatan dalam memberikan banyak instruksi yang harus diingat oleh pasien. Kesadaran diri oleh pasien tentang diet sangatlah penting dimana pasien yang paham instruksi banyak yang tidak patuh terhadap diet yang dijalani. Oleh karena itu tenaga kesehatan diharapkan lebih meningkatkan perannya dalam memberikan edukasi tentang diet yang tepat kepada pasien dengan gagal ginjal kronik yang menjalani terapi hemodialisa dengan bahasa yang mudah dimengerti serta melibatkan keluarga saat memberikan edukasi kepada pasien. Dengan pahamnya pasien instruksi tentang diet yang tepat akan meningkatkan kepatuhannya dalam menjalani diet.

\section{Kualitas Interaksi}

Kualitas interaksi antara profesional kesehatan dan pasien merupakan bagian yang penting dalam menentukan derajat kepatuhan (Niven,2002). Teori ini tidak sejalan dengan hasil penelitian yang didapatkan dimana berdasarkan hasil analisa data diketahui bahwa mayoritas responden memiliki kulitas interaksi yang baik, namun responden yang patuh dengan kualitas interaksi yang baik sedikit jumlahnya. Hal ini menunjukkan bahwa tenaga kesehatan telah berhasil membangun hubungan komunikasi yang baik dengan responden dalam memberikan informasi tentang diet bagi pasien gagal ginjal kronik namun edukasi dan feed back (umpan balik) ditingkaktkan. Informasi yang disampaikan oleh tenga kesehatan kepada pasien harus sesuai dengan kondisi pasien yang sedang menjalani terapi hemodialisa yaitu tentang diet yang sesuai kebutuhan pasien dan tidak membicarakan hal lain di yang tidak bermanfaat dengan pasien saat penyampaian informasi. Kesadaran diri oleh pasien tentang diet sangatlah penting dimana pasien yang memiliki kualitas interaksi yang baik banyak yang tidak patuh terhadap diet yang dijalani. Menurut Notoatmodjo (2007), orang yang telah paham terhadap objek atau materi harus dapat menjelaskan, menyebutkan contoh, menyimpulkan, meramalkan dan sebagainya terhadap objek yang dipelajari.

\section{Dukungan Keluarga}

Hasil penelitian menunjukkan bahwa mayoritas dukungan keluarga yang diperoleh oleh responden termasuk dalam kategori kurang mendukung. Hal ini berbanding terbalik dengan penelitian Desitasari, Utami, \& Misrawati (2014) pada RSUD Arifin Achmad Pekanbaru tentang hubungan pengetahuan, sikap dan dukungan keluarga dengan kepatuhan diet pasien gagal ginjal kronik yang menjalani hemodialisa dari 36 responden peneliti mendapatkan dukungan keluarga responden mayoritas tinggi sebanyak 23 orang $(63,9 \%)$ dan dukungan keluarga responden rendah sebanyak 13 orang $(36,1 \%)$.

Niven (2002) menyatakan bahwa keluarga dapat menjadi faktor yang sangat berpengaruh dalam menentukan keyakinan dan nilai kesehatan individu serta dapat juga menentukan tentang program pengobatan yang dapat mereka terima. Kurangnya edukasi kepada keluarga pasien dari tenaga kesehatan tentang diet pasien mengakibatkan keluarga tidak tahu peranannya. Kesadaran diri oleh pasien tentang diet sangatlah penting dimana pasien yang mendapat dukungan dari keluarga banyak yang tidak patuh terhadap diet yang dijalani

Keluarga harus memberi dukungan kepada pasien yang menjalani hemodialisa agar pasien lebih patuh dalam menjalani dietnya karena keluarga adalah orang yang paling dekat dengan pasien dan mempunyai waktu yang lebih banyak dengan pasien.

\section{Kepatuhan}

Kepatuhan adalah ketaatan pasien dalam melaksanakan tindakan terapi. Kepatuhan pasien berarti bahwa pasien dan keluarga harus meluangkan waktu dalam menjalani pengobatan yang di butuhkan (Potter \& Perry, 2005). Dari hasil penelitian diperoleh mayoritas responden gagal ginjal kronik yang menjalani terapi hemodialisa termasuk dalam kategori tidak patuh dalam menjalani diet. Hal ini berbanding terbalik dengan penelitian Kamaludin \& Rahayu (2009) tentang analisis faktor-faktor yang mempengaruhi kepatuhan asupan cairan pada pasien gagal ginjal kronik dengan hemodialisa dari 51 responden peneliti mendapatkan $67,3 \%$ penderita yang patuh dan $32,7 \%$ yang tidak patuh dalam mengurangi asupan cairan pada RSUD Prof Dr. Margono Soekarjo Puwerkerto.

Kurangnya kepatuhan responden dalam menjalani diet dikarenakan kurangnya pemahaman responden terhadap instruksi dari tenaga kesehatan serta dukungan dari keluarga. Meskipun mayoritas kualitas interaksi antara pasien dan tenaga kesehatan baik namun tidak semua pasien patuh dalam menjalani diet yang tepat. Terapi yang dijalani akan sia-sia jika pasien tidak patuh terhadap diet. Hal ini sesuai dengan pendapat Almatsier (2008) yang menyatakan bahwa seseorang yang telah menjalani terapi hemodialisa kemudian tidak menjalankan program diet dengan baik maka akan terjadi defisiensi gizi, 
keseimbangan cairan dan elektrolit akan terganggu dan akan terjadi akumulasi produk sisa metabolisme (uremia) yang berlebihan sehingga akan mempercepat dari jadwal terapi yang akan ditentukan dan akan memperberat biaya dari terapi.

\section{KESIMPULAN}

Hasil penelitian faktor-faktor yang memengaruhi kepatuhan diet pasien gagal ginjal kronik yang mendapat terapi hemodialisa di ruang hemodialisa RSUD Dr. Pirngadi Kota Medan tahun 2015 dengan jumlah responden sebanyak 35 orang.

Dari hasil penelitian dapat disimpulkan bahwa faktor yang memengaruhi kepatuhan pasien mayoritas adalah kualitas interaksi, pasien yang memiliki pemahaman instruksi yang baik, kualitas interaksi yang baik dan dukungan keluarga, yang patuh terhadap diet sedikit jumlahnya, kesadaran diri pasien terhadap diet yang dijalani sangatlah penting, mayoritas pasien tidak patuh dalam menjalani diet.

\section{SARAN}

Bagi Pasien dan Keluarga, pasien harus lebih patuh terhadap diet yang dijalani. Bagi keluarga dapat menjadi motivator yang baik untuk mendukung pasien agar lebih patuh serta membantu mengatur diet pasien agar tetap terjaga.

Bagi Perawat, perawat diharapkan menjadi edukator yang dapat memberikan edukasi tentang diet yang baik kepada pasien yang menjalani terapi hemodialisa sehingga dapat meningkatkan kepatuhan dan kualitas hidup pasien yang menjalani terapi hemodialisa dan juga mengevaluasi setiap materi yang sudah di sampaikan kepada pasien.

Untuk meningkatkan kualitas interaksi sebaiknya tenaga kesehatan selalu mengingatkan pasien tentang dietnya, dan tenaga kesehatan membuat buku panduan, brosur, ataupun leafleat kepada pasien tentang diet yang baik dan sesuai dengan kebutuhan responden yang sedang menjalani hemodialisa.

\section{DAFTAR PUSTAKA}

Ali, M. 2014. Perbedaan Tekanan Darah Pasien Gagal Ginjal Kronik Sebelum dan sesudah Hemodiaisa di Ruang Hemodialisa BLUD Dr. Pirngadi Medan. Skripsi.

http://repository.usu.ac.id/bitstream/123456789/404 91/5/Chapter\%20I.pdf diakses tanggal 7 januari 2015

Almatsier, S. 2008. Penuntun Diet edisi baru. Jakarta: PT. Gramedia Pustaka Utama

Barnett. T et al. 2007. Fluid compliance among patient having hemodialysis : can an educational programme make a difference? Blackwell Publishing http://ebscohost diakses tanggal 8 Januari 2015
Brunner \& Suddarth, 2002. Keperawatan Medikal Bedah. Jakarta: EGC

Cahyaningsih, ND. 2011. Hemodialisis (cuci darah). Jogjakarta: Mitra Cendekia Press

Desitasari, Utami, \& Misrawati. 2014. Hubungan Tingkat Pengetahuan, Sikap dan Dukungan Keluarga Terhadap Kepatuhan Diet Pasien Gagal Ginjal Kronik yang Menjalani Hemodialisa. http://download.portalgaruda.org/article.php?article $=186714 \& \mathrm{val}=6447 \&$ title=Hubungan $\% 20$ Tin diakses tanggal 12 Januari 2015

Hidayat. 2011. Metode Penelitian Keperawatan dan Teknik Analisis Data. Jakarta: Salemba Medika

Indonesian Renal Registry (IRR). 2012. 5th Report Of Indonesian Renal Registry 2012. Perkumpulan Nefrologi Indonesia (PERNEFRI). http://www.pernefriinasn.org/Laporan/5th\%20Annual\%20Report\%20 Of\%20IRR\%202012.pdf di akses tanggal 26 Januari 2015

Kim, Y., Evangelista 1.S., Phillips, L.R., Pavlish, C., \& Kopple, J.D. 2010. The End-Stage Renal Disease Adherence Questionnaire (ESRD-AQ): Testing the psychometric properties in patients receiving incenter hemodialysis. Nephrology Nursing Journal, 37 (4), 377-393. http://search.proquest.com/docview/746427672/96 672E7D639149C3PQ/1?accountid=50257 diakses tanggal 15 januari 2015

Kamaludin, R \& Rahayu, E. 2009. Analisis Faktor-faktor yang Mempengaruhi Kepatuhan Asupan Cairan pada Pasien Gagal Ginjal Kronik dengan Hemodialisa di RSUD Prof. Dr. Margono Soekarja Purwokerto.

http://jos.unsoed.ac.id/index.php/keperawatan/articl e/download/175/40 di akses tanggal 10 januari 2015

Lemone, P. \& Burke, K.M. 2008. Medical surgical nursing : critical thinking in clien care, 6 edition, New Jersey : Prentice Hall Health.

Mansjoer, Triyanti, Savitri, Wardhani, \& Setiowulan. 2008. Kapita Selekta Kedokteran. Jakarta: Media Aesculapius FK UI

Mutaqqin, A \& Sari, K. 2011. Asuhan Keperawatan Gangguan Sistem Perkemihan. Jakarta: Salemba Medika

Niven, N. 2002. Psikologi Kesehatan. Jakarta: EGC

Notoatmodjo, S. 2007. Kesehatan Masyarakat Ilmu \& Seni. Jakarta: Rineka Cipta

2010. Metodologi Penelitian Kesehatan. Jakarta: Rineka Cipta

Noviyanti, W. 2013. Faktor-faktor yang mempengaruhi Ketidakpatuhan Pasien Hemodialisa dalam Menjalani Pola Diet di RSUD Kota Dumai. Skripsi.

http://repository.usu.ac.id/bitstream/123456789/393 44/5/Chapter\%201.pdfdi unduh tanggal 5 januari 2015 
Nursalam. 2008. Konsep dan Penerapan Metodeologi Penelitian Ilmu Keperawatan. Jakarta: Salemba Medika

Nursalam \& Batticaca, F.B. 2009. Asuhan Keperawatan pada Pasien dengan Gangguan Sistem Perkemihan. Jakarta: Salemba Medika

Potter \& Perry. 2005. Buku Ajar Fundamental Keperawatan. Jakarta: EGC

Smeltzer, S.C \& Bare, B.G. 2008. Texbook of medikcal surgical nursing $\left(11^{\text {th }}\right.$ ed). Philladelphia: Lipincott Williams \& Wilknis

Sugiyono. 2010. Metode Penelitian Kuantitatif, Kualitatif dan $R \& D$. Bandung: Alfabeta
Syamsir, A \& Iwan, H. 2008. Gagal ginjal. Jakarta: PT. Gramedia Pustaka Utama

Sudoyo, Setiyohadi, Alwi, Simadibrata K, \& Setiati. 2009. Buku Ajar Ilmu Penyakit Dalam. Jakarta: InternaPublishing

Vitahealth, 2008. Gagal Ginjal. Jakarta: PT. Gramedia Pustaka Utama 